NBER WORKING PAPERS SERIES

DYNAMIC EFFICIENCY, THE RISKLESS RATE, AND

DEBT PONZI GAMES UNDER UNCERTAINTY

Olivier Jean Blanchard

Philippe Weil

Working Paper No. 3992

NATIONAL BUREAU OF ECONOMIC RESEARCH 1050 Massachusetts Avenue

Cambridge, MA 02138

February 1992

We thank Andrew Abel, Willem Buiter, Stanley Fischer, Giampaollo Galli, Fumio Hayashi, Lawrence Summers and Oved Yosha for helpful discussions, and gratefully acknowledge support from the National Science Foundation. This paper is part of NBER's research programs in Asset Pricing and Economic Fluctuations. Any opinions expressed are those of the authors and not those of the National Bureau of Economic Research. 
NBER Working Paper \#3992

February 1992

\title{
DYNAMIC EFFICIENCY, THE RISKLESS RATE, AND \\ DEBT PONZI GAMES UNDER UNCERTAINTY
}

\begin{abstract}
Can governments roll their debt over forever in dynamically efficient economies, and thus avoid the need to raise taxes? While the answer is a clear no under certainty, it depends, under uncertainty, on whether public debt provides intergenerational insurance. When it does not, rollover is not possible, even if the rate of return on one-period bonds is below the growth rate. When it does, debt rollover may be possible, even if the return on one-period bonds is above the growth rate.
\end{abstract}

Olivier Jean Blanchard

Department of Economics

M.I.T.

50 Memorial Drive

Cambridge, MA 02139

and NBER
Philippe Weil

Department of Economics

Littauer Center 117

Harvard University

Cambridge, MA 02138

and NBER 
In all major $O E C D$ countries, the average realized real rate of return on government debr over the last 20 years has been smaller than the growth rate. Does this imply that governments can play a Ponzi debt game, rolling over their debt without ever increasing taxes?

If only economies were both non stochastic and in steady state, the answer to the question would be a simple one. All interest rates would be the same, and if the interest rate were less than the growth rate, the economy would be dynamically inefficient. And in this case indeed, the government could issue debt and roll it over forever, never increasing taxes, and covering interest payments by new debt issues. Debt would grow at the interest rate, but the ratio of debt to GNP would eventually tend to zero. And, as we also know, such a policy would in general be Pareto improving.

Actual economies however are stochastic. And in stochastic economies, there are many different interest rates, some which are on average above the growth rate, some which are below. Recent research has shown in particular that economies may well be dynamically efficient, while having an average riskless real rate below the growth rate. But this brings us back to our initial question. In such economies, can't governments issue and roll over riskless debt, and thus play a Ponzi debt game? This is the question we take up in this paper.

The paper is organized around four examples. All share the following features. First, all characrerize economies which are subject to technological shocks and thus to uncertainty, so that assets with different risk characteristics have different rates of return. Second, all characterize overlapping generation economies with capital accumulation, thus economies for which capital overaccumulationdynamic inefficiency - is not ruled out a prioti. But, third, in each case, we choose, relying on a criterion derived by Zilcha [1990], underlying taste and technology parameters such the economy is actually dynamically efficient. In each of these economies, we then ask what would happen to the debt-to-GNP ratio if the government were to issue debt and roll it over time, issuing new debt to pay interest on the existing debt. And each of the four examples gives us a very different answer.

In our first example, the average riskless tate is negative; nevertheless the expected value of the debt-to-GNP ratio under a rollover strategy explodes and thus the government cannot play a debt Ponzi game. In the second, the average riskless rate is again negative, and, furthermore, the expected value of the debt- 
to-GNP ratio under rollover goes to zero. But the fact that a Ponzi game appears viable in expected value does not imply that it is feasible. Indeed, in this example, with strictly positive probability, debt rollover leads to an arbitrarily large value of the debt-to-GNP ratio and is thus again infeasible. By then, the reader may suspect that dynamic efficiency rules out Ponzi games, no matter what the behavior of the average niskless rate may be. But the last two examples show this guess to be wrong. In our third example, the average riskless rate is negative and under a Ponzi debt game, the debt-to-GNP ratio goes to zero with certainty, so that rollover is indeed feasible. Our fourth example offers a nearly perfect counterpoint to the first; in that example the riskless rate-the rate on one-period bonds-is positive; yet by issuing and rolling over two-period bonds, the government can still play a Ponzi debt game...

Having presented these examples, we show the simple structure underlying these seemingly conflicting results. The overlapping generation structure of these economies has two implications. The first is that individual saving may lead to aggregage capital overaccumulation, to dynamic inefficiency. The second is that it leads to incomplete market participation. In particular, because individuals cannot enter insurance contracts before they are born, there may be incomplete risk sharing. Thus, even if the economy is dynamically efficient, the allocation may not be Pareto optimal. It is this distinction between dynamic efficiency and Pareto optimality which is crucial in understanding our results. In our first two examples, the specification of tastes and technology leads to an allocation such that there is no further opportunity for risk sharing, and the incompleteness of markets does not matter. The allocation is thus not only dynamically efficient but also Pareto optimal. This is however not the case in our last two examples, where incomplete market participation matters. Those economies are dynamically efficient but they are not Pareto optimal. When this is the case, government debt may provide some insurance and thus be a partial substitute for incomplete markets. In that case, a Ponzi game may actually be both feasible and Pareto improving. It is also not surprising that, in that case also, the risk characteristics of the debt matter, and this is the key to understanding our last example. In that example, two-period debt actually provides more insurance than one-period debt, thus allowing for a Ponzi-debt game when two-period bonds are used.

Our paper is related to a number of strands of research, from the existence of fiat currency equilibria under uncertainty to theories of optimal debt maturity under uncertainty. Indeed, some of our findings just shed new light on existing results, 
or recast them in a different mold. We will point these relations as we go along.

\section{A first example: a Diamond model with logarithmic preferences}

Our first example is a straightforward extension of the Diamond [1965] model to uncertainty. ${ }^{1}$ Consider an overlapping generation economy in which two-period consumers inelastically supply one unit of labor when young and retire when old, and in which population is constant and equal to one. Assume that consumers have time- and state-additive logarithmic preferences. An individual representative of the generation born at time $t$ therefore maximizes

$$
(1-\beta) \ln C_{1, t}+\beta E_{t} \ln C_{2, t+1}
$$

subject to

$$
\begin{aligned}
C_{1 t}+K_{t+1} & =W_{t} \\
C_{2, t+1} & =R_{t+1} K_{t+1}
\end{aligned}
$$

where $C_{1, t}$ and $C_{2, t+1}$ denote first and second period consumptions of an individual born at $t, W_{t}$ and $R_{t}$ the wage and capital rental rates at $t, K_{t}$ the capital stock at $t$, and $\beta \in(0,1)$ measures subjective time preference.

Output is produced according to a Cobb-Douglas technology. Output at time $t$ is given by:

$$
Y_{t}=\Upsilon_{t} K_{t}^{\alpha}
$$

where $K_{t}$ denotes capital per worker at time $t$, and $\alpha \in(0,1)$ the constant share of capital in output. The logarithm of the productivity shock $\Upsilon$ is assumed to be independently and identically normally distributed, with mean zero and variance $\sigma^{2}$. Capital fully depreciates in production.

1. This model is by now standard. See for example Blanchard and Fischer [1989] 


\subsection{Equilibrium capital accumulation and dynamic efficiency}

Solving for first-and second-period consumption from utility maximization, and replacing wages and rental rates by their values from profit maximization, gives:

$$
\begin{aligned}
K_{t+1} & =(1-\alpha) \beta \Upsilon_{t} K_{t}^{\alpha} . \\
C_{1, t} & =(1-\beta)(1-\alpha) \Upsilon_{t} K_{t}^{\alpha} \\
C_{2, t} & =\alpha \Upsilon_{t} K_{t}^{\alpha}
\end{aligned}
$$

Note-this will be relevant later-that, at any time $t$, the consumptions of the young and the old are perfectly correlated. Our interest for the moment is how. ever in the behavior of capital. Denote, hereafter, the logarithm of an uppercase variable by its lowercase counterpart. We then have

$$
k_{t+1}=\ln [(1-\alpha) \beta]+\alpha k_{t}+v_{t} \text {. }
$$

And the behavior of output is given by

$$
y_{t}=\alpha \ln [(1-\alpha) \beta]+\alpha y_{t-1}+v_{t} .
$$

Capital accumulation leads to serial correlation of capital and output in response to white noise shocks. A positive technological shock increases output, saving and thus capital and output in the following period.

Having characterized the behavior of capital, we can now ask under what parameter values this economy is dynamically efficient. This first requires defining dynamic efficiency under uncertainty. The natural extension of the aggregative Cass [1972] criterion is that the economy is dynamically efficient if there does not exist another feasible sequence of capital which provides at least as much aggregate consumption at all dates and in all states, and strictly higher aggregate consumption in at least one date or state. Zilcha [1990] has recently derived a necessary and sufficient condition for the efficiency of stationary economies such as the one we consider. In this economy with constant population, the condition is that the expected logarithm of the gross marginal product of capital, $\mathrm{E} r_{t}$, be nonnegative. Here,

$$
\mathrm{E} r_{t}=\ln \alpha+(\alpha-1) \mathrm{E} k_{t}=\ln \left[\frac{\alpha}{(1-\alpha) \beta}\right],
$$


so that the economy is dynamically efficient if and only if

$$
\theta \equiv \frac{\alpha}{(1-\alpha) \beta}-1 \geq 0
$$

Interestingly, this condition does not depend on the moments of the underlying technological shocks, and is exactly the same as that which would hold under certainty, i.e., if $\Upsilon$ were identically equal to one. ${ }^{2}$ In the rest of this section, we assume that condition (1.11) is satisfied and that the economy is dynamically efficient. We now turn to the determination of the riskless rate.

\subsection{The riskless rate}

The equilibrium riskfree rate of return $R_{t+1}^{f}$, required for people to hold a safe one-period bond paying one unit of the consumption good in every state next at $t+1$ must satisfy the first-order condition for utility maximization:

$$
(1-\beta) C_{1, t}^{-1}=\beta R_{t+1}^{f} \mathrm{E}_{t} C_{2, t+1}^{-1},
$$

with consumption evaluated along the optimal path if the bond is in infinitesimal supply.

Replacing first-and second-period consumption in (1.12) by their values from equations (1.6) and (1.7), we get

$$
R_{t+1}^{f}=\frac{1}{E_{t} \Upsilon_{t+1}^{-1}} \alpha K_{t+1}^{\alpha-1}
$$

which, using our distributional assumptions about $v$, implies

$$
r_{t+1}^{f}=\ln \alpha+(\alpha-1) k_{t+1}-\sigma^{2} / 2
$$

Using (1.5), (1.14) and (1.11), the unconditional mean and variance of the logarithm of the riskfree rate are thus given by

$$
\begin{aligned}
\mathrm{E} r_{t+1}^{\prime} & =\ln (1+\theta)-\sigma^{2} / 2, \\
\operatorname{Var} r_{t+1}^{\prime} & =\frac{1-\alpha}{1+\alpha} \sigma^{2}
\end{aligned}
$$

2. It is also interesting to note that the condition for dynamic efficiency of Abel et al. [1989]which, being a sufficient condition, is often not conclusive in particular models-is satisfied here. Gross profits, $R_{t} K_{t}=\alpha \Upsilon_{1} K_{t}^{\alpha}$, exceed gross investment, $K_{t+1}=\beta(1-\alpha) \Upsilon_{t} K_{t}^{\alpha}$, at all dates and in all states if and only if $\alpha>\beta(1-\alpha)$, i.e., if and only if $\theta>0$. 
so that, finally,

$$
\mathrm{E} R_{t+1}^{f}=(1+\theta) \exp \left[-\frac{\alpha}{1+\alpha} \sigma^{2}\right] \text {. }
$$

Were there no uncertainty, the net riskless rate would be equal to $\theta$, and thus would be positive under dynamic efficiency. But if the variance of the technological shocks is large enough, the average gross riskless rate under uncertainty may be less than one, and the net rate may be negative.

\subsection{Debt Ponzi games}

Assume that the underlying parameters are such that both the economy is dynamically efficient and that the average net riskless rate is negative. Does the average negative riskless rate imply that the government can roll its debt over forever without ever levying taxes?

Our strategy in assessing whether or not Ponzi debt games are feasible in each of our examples will be to characterize the behavior of debt using the interest rates corresponding to a zero net supply of debt, thus corresponding to the case where consumption and capital dynamics are given by (1.5) to (1.7). If we can show that Ponzi games are not feasible under such interest rates, this will a fortiori be true were we to do the same exercise at the interest rates corresponding to a positive supply of debt (an exercise however considerably more difficult analytically): under our assumption on the utility function which implies that saving is a constant fraction of labor income, Ponzi games and asset bubbles crowd out capital accumulation (see Weil [1987]) and thus raise, ceteris paribus, all interest rates. If instead we can show that Ponzi games are feasible under such interest rates, that the debt-to-GNP ratio implodes over time under rollover, then this will remain true if the government issues a small enough amount of debt at time 0 .

Let $B_{0}$ be the amount of one-period riskless bonds issued at time 0 . Then, under a rollover strategy, the debt-to-GNP ratio at time $t$ follows

$$
\begin{aligned}
B_{t} / Y_{t} & =\left(R_{t}^{f} \ldots R_{1}^{f}\right) B_{0} / Y_{t}, \\
& =\left[R_{t}^{f} /\left(Y_{t} / Y_{t-1}\right)\right] \ldots\left[R_{1}^{f} /\left(Y_{1} / Y_{0}\right)\right]\left(B_{0} / Y_{0}\right)
\end{aligned}
$$

Using the characterization of output and the riskless rate given in equations (1.9) and (1.14), this implies:

$$
b_{t}-y_{t}=\left(b_{0}-y_{0}\right)+t\left[\ln (1-\theta)-\sigma^{2} / 2\right]-\sum_{s=1}^{t} v_{s} .
$$


The logarithm of the debt-to-GNP ratio follows a random walk with drift, with innovations equal to the technological shocks. This in turn implies that the expected value of the debt-to-GNP ratio follows:

$$
\mathrm{E}\left[B_{t} / Y_{t}\right]=\left[B_{0} / Y_{0}\right](1+\theta)^{t}
$$

Thus, the behavior of the expected debt-to-GNP ratio is simple: it grows at rate $\theta$, irrespective of the value of the average riskless rate. ${ }^{3}$ This implies that a Ponzi game is not feasible: in expectation, debt becomes larger than saving, which is proportional to GNP — an impossibility.

What is at work here is Jensen's inequality. As is clear from equation (1.14), the riskless rate from $t$ to $t+1$ is known at time $t$, but varies stochastically through time. What matters for the behavior of debt is the expectation of the product of the riskless rates, not the product of the expected riskless rates. This is why a negative average riskless rate is consistent with an exploding expected debt-toGNP ratio. ${ }^{4}$

This first example gives a clear warning. An economy may have an average negative riskless rate (or, if we were to allow for growth, an average riskless rate below the average growth rate) but this does not imply that the government can rollover debt forever; in this example, under the condition that the economy is dynamically efficient, the expected debt-to-GNP ratio grows at a rate which is necessarily positive, regardless of the riskless rate. One may ask however what would happen if people were more risk averse than implied by logarithmic utility. Wouldn't this further decrease the average riskless rate and reintroduce room for a Ponzi game? We take the issue up in the next example.

\section{A second example: allowing for more risk aversion}

In this example, we modify the previous model in one respect: we maintain the assumption that consumers still have logarithmic intertemporal preferences, but

3. The behavior of debt itself as opposed to the debt-to-GNP ratio is more complex. If the average riskless rate is negative, expected debt initially decreases. Asymptotically however, it also grows at rate $\theta$.

4. A similar point has been made in Galli and Giavazzi [1990] in the context of a Ramsey economy. 
no longer restrict their coefficient of relative risk aversion to equal unity. The rationale for adopting this more flexible specification is that, while the assumption of a unit elasticity of intertemporal substitution is necessary to preserve the simplicity of the model (it makes "myopic" decision rules optimal), the ability to choose the degree of risk aversion allows us to examine the comparative dynamic effects of increased risk aversion on equilibrium returns and on the asymptotic rate of growth of debt Ponzi games.

Thus, following Selden's [1978] axiomatization of OCE preferences and Weil [1990], we assume that consumers now maximize

$$
(1-\beta) \ln C_{1, t}+\beta \ln \left[\mathrm{E}_{t} C_{2, t+1}^{1-\gamma}\right]^{1 /(1-\gamma)},
$$

where $\gamma>0(\gamma \neq 1)$ is the coefficient of relative risk aversion. ${ }^{5}$

\subsection{Equilibrium capital accumulation and dynamic efficiency}

Because of the assumption of logarithmic intertemporal preferences, consumers choose to save a constant fraction $\beta$ of their lifetime wealth regardless of the coefficient of relative risk aversion: attitudes towards risk do determine the certainty equivalent of the marginal productivity of capital, but are irrelevant for consumption and savings decisions when income and substitution effects cancel each other out. As a consequence, the equilibrium consumption allocation and capital accumulation process are the same as in the previous section, and the condition for dynamic efficiency is still, as in (1.11), $\theta>0$.

\subsection{The riskless rate}

While the value of $\gamma$ does not matter for capital accumulation when intertemporal preferences are logarithmic, attitudes towards risk are of course a crucial determinant of the implicit riskless interest rate. Adapting the argument in the previous section, the equilibrium gross return on a safe claim on consumption at $t+1$ must satisfy

$$
\frac{1-\beta}{C_{1, t}}=\beta R_{t+1}^{f, \gamma} \frac{\mathrm{E}_{t} C_{2, t+1}^{-\gamma}}{\mathrm{E}_{t} C_{2, t+1}^{1-\gamma}}
$$

5. Note that $\left[\mathrm{E}_{t} C_{2, t+1}^{1-\gamma}\right]^{1 /(1-\gamma)}$ is simply the certainty equivalent of second period consumption for an individual with constant relative risk aversion $\gamma$. One can also verify, using LHospital's rule, that the preferences represented in (2.1) reduce to the rime-and state-additive logarithmic form in (1.1) when $\gamma \rightarrow 1$. 
where the notation $R_{t+1}^{f, \gamma}$ is adopted to highlight the dependence of the riskless rate on $\gamma$.

Evaluating this expression along the no debt path, one finds that:

$$
R_{t+1}^{f, \gamma}=\frac{E_{t} \Upsilon_{t+1}^{1-\gamma}}{E_{t} \Upsilon_{t+1}^{-\gamma}} \alpha K_{t+1}^{\alpha-1}
$$

Under the lognormality assumption, it follows that:

$$
R_{t+1}^{f, \gamma}=R_{t+1}^{f, 1} \mathrm{e}^{(1-\gamma) \sigma^{2}}
$$

with the expression for $R_{t+1}^{f, 1}$ given by (1.14).

As a consequence,

$$
\begin{aligned}
\mathrm{E} R_{t+1}^{f, \gamma} & =\mathrm{E} R_{t+1}^{f, 1} \mathrm{e}^{(1-\gamma) \sigma^{2}} \\
& =(1+0) \mathrm{e}^{[-(\alpha /(1+\alpha))] \sigma^{2}} \mathrm{e}^{[(1-\gamma)] \sigma^{2}} .
\end{aligned}
$$

The effect of increased risk aversion is thus to decrease proportionately the riskless rate by the same factor in all states and at all dates. For a given variance of productivity shocks, the average net riskless rate can be very negative if agents are very risk averse.

\subsection{Debt Ponzi games}

Following the same logic as in the previous section, we derive the behavior of the debt-to-GNP ratio under rollover using the processes for the riskless rate and for output characterized above. We get that the logarithm of the debt-to-GNP ratio at time $t$ under Ponzi finance follows:

$$
b_{t}-y_{t}=\left(b_{0}-y_{0}\right)+t\left[\ln (1+\theta)+(1-2 \gamma) \sigma^{2} / 2\right]-\sum_{s=1}^{t} v_{s}
$$

As before, the debt-to-GNP ratio follows a random walk with drift. However, for a given variance of shocks, the drift may now be arbitrarily large and negative. Equation (2.6) in turn implies:

$$
\mathrm{E}\left[B_{t} / Y_{t}\right]=\left[B_{0} / Y_{0}\right](1+\theta)^{t} \mathrm{e}^{(1-\gamma) \sigma^{2} t}
$$


The unconditional expected debt-to-GNP ratio thus grows (or declines...) at the constant rate $(1+\theta) \mathrm{e}^{(1-\gamma) \sigma^{2}}$. Provided that agents are sufficiently risk averse, dynamic efficiency $(\theta>0)$ need not imply an exploding expected debt-to-GNP ratio under rollover. Does this mean that Ponzi games are feasible in this economy? The answer is no. It is not enough that the expected value of the ratio go to zero. What is required is that the Ponzi game be feasible in all states. ${ }^{6}$ Equation (2.6) shows that the logarithm of the debt-to-GNP ratio follows a random walk with drift. It follows that the debt to GNP ratio will exceed any finite limit, such as the ratio of saving to GNP, with probability 1 if the expected debt-to-GNP ratio rises, and with positive probability if the expected debt to GNP ratio decreases. Thus, with strictly positive probability, even if the expected debt to GNP ratio goes to zero, the Ponzi game will prove infeasible.

This second example shows that, in an economy which is dynamically efficient, the riskless rate may be negative, the debt-to-GNP ratio may go to zero in expected value under rollover, and yet there is a strictly positive probability that the Ponzi game cannot be played forever. The proximate cause of the result is that the debt-to-GNP ratio follows a random walk with drift. This in turn raises another question. Could the government issue bonds with different risk characteristics so that, under some conditions, the debt to GNP ratio would instead be stationary around a mean and the probability that it reaches some critical value be made arbitrarily small or even zero? This is the question we take up in the next section.

\section{A brief detour: contingent bonds and debt Ponzi games.}

When the government rolls over riskless debt in our previous example, the debtto-GNP ratio follows a non-stationary process. Thus, no matter how small the initial amount of debt issued, there is a positive probability that the ratio eventually exceeds some given bound. Can the government instead issue a different type of debt, perhaps contingent debt, such that the debt process is stationary, perhaps around some trend? With this question in mind, consider the issue by the government of one-period bonds whose dividend is perfectly correlated with the inverse of the marginal rate of substitution-or, equivalently in this economy,

6. This is indeed the main point raised by Bohn [1990]. 
with output growth. Namely, assume that a one-period bond pays

$$
\frac{Y_{t+1}}{Y_{t}}=\frac{\Upsilon_{t+1} K_{t+1}^{\alpha}}{\Upsilon_{t} K_{t}^{\alpha}}
$$

Assume, as in section 2, that consumers tastes exhibit a unit elasticity of substitution, and a constant coefficient of relative risk aversion $\gamma$ (the model of section 1 obtains as the special case $\gamma=1$ ). Following the same argument as supra, the price at time $t$ of a one-period "output growth" bond must be, in equilibrium,

$$
p_{t}=\frac{\beta}{1-\beta} \frac{\mathrm{E}_{t}\left\{\left[C_{2, t+1} / C_{1, t}\right]^{-\gamma}\left[Y_{t+1} / Y_{t}\right]\right\}}{\mathrm{E}_{t}\left[C_{2, t+1} / C_{1, t}\right]^{1-\gamma}} .
$$

Using equations (1.6), (1.7), (1.5) and (3.1), it follows that

$$
p_{t}=\frac{(1-\alpha) \beta}{\alpha}=(1+\theta)^{-1} \text {. }
$$

Therefore, the (random) one-period rate of return on public debt is given by

$$
R_{t+1}^{b}=(1+\theta) \frac{Y_{t+1}}{Y_{t}} \text {. }
$$

Under a debt rollover strategy, given the process for the rate of return and for output, the debt-to-GNP ratio at time $t$ is simply

$$
B_{t} / Y_{t}=(1+\theta)^{t}\left[B_{0} / Y_{0}\right] \text {. }
$$

Irrespective of the variance and realizations of productivity shocks, and independently of attitudes towards risk, the debt-to-GNP ratio grows at rate $\theta$ : it thus collapses deterministically towards zero if the economy is inefficient. This implies that a necessary and sufficient condition for the feasibility of such a debt Ponzi scheme is that the economy be dynamically inefficient. If the economy is dynamically efficient to start with, so that $\theta$ is positive, introducing debt increases the equilibrium rate of return, and thus the debt-to-GNP ratio explodes at a rate greater than $\theta$ under Ponzi finance. If the economy is dynamically inefficient to start with, so that $\theta$ is strictly less than zero, the issuance of a small enough amount of debt still leads to implosion of the debt-to-GNP ratio so that some Ponzi finance is indeed feasible.

At this stage, a natural guess may be that, no matter what the average riskless rate is, and whether the expected debt-to-GNP ratio explodes or implodes, dynamic efficiency is a necessary and sufficient condition for the feasibility of Ponzi finance. The last two examples show this not to be the case. 


\section{A third example: an economy with stochastic storage}

As in our first example, assume that the economy is composed of overlapping generations of two-period consumers, with time- and state-additive logarithmic preferences. The technology is however different. People born at time $t$ receive a non-stochastic first period endowment $W>0$, and have access to a stochastic constant returns to scale storage technology with random gross rate of return $\tilde{R}_{t+1} \cdot{ }^{7}$ The logarithm of $\tilde{R}_{t}$ is assumed to be identically and independently distributed with mean $\mu$ and variance $\sigma^{2}$.

Using the Zilcha [1990] criterion, this economy is dynamically efficient if and only if $\mathrm{E} \ln \tilde{R}_{t}=\mu \geq 0$. $^{8}$

Under those assumptions, the consumption of the young, the consumption of the old and the capital stock are given by:

$$
\begin{aligned}
C_{1 t} & =(1-\beta) W \\
C_{2 t} & =\beta \tilde{R}_{t} W, \\
K_{t} & =\beta W,
\end{aligned}
$$

Because the endowment is non stochastic, the consumption of the young and capital accumulation are also non stochastic. Because storage is stochastic, the consumption of the old is stochastic, and independently and identically distributed over time. In contrast to the previous examples, the consumption of young and old are not perfectly correlated, a point to which we shall return below.

Having characterized consumption, we can derive the implicit equilibrium rate of return on a one-period bond. From the first order conditions of the consumer, it is given by:

$$
R^{f}=\frac{1}{\mathrm{E} \tilde{R}^{-1}}=\mathrm{e}^{\mu-\sigma^{2} / 2}
$$

7. This model is also standard. It was used by Koda [1984] to study the existence of fiat currency equilibria, and was more recently analyzed by Gale [1990] and Blanchard [1990] in the context of public debt. A similar model was also used by Summers [1984].

8. Formally, our example, which has constant returns to storage does not satisfy the concavity conditions required for the Zilcha criterion to apply. An alternative formalization, which satisfies those conditions, and has the same implications for the existence of debt rollover is that one where depreciation is stochastic so that output is produced according to $Y_{t}=K_{t}{ }^{\alpha}-\delta K_{t}$ where $\delta$ is a random variable. Also, note that the inefficiency criterion of Abel et al. [1989] is inconclusive in this economy. 
Thus the rate of return on one-period bonds is also non stochastic. It may well be negative if the variance of $\tilde{R}$ is sufficiently large. ${ }^{9}$ Since both the first-period endowment and the riskless rate are constant, a necessary and sufficient condition for the feasibility of issuing at least a small quantity of debt and rolling it over is simply

$$
R^{f}<1
$$

Thus, in sharp contrast to our previous examples, in this dynamically efficient economy, debt Ponzi games may actually be feasible. And the riskless rate plays a crucial role in determining the feasibility of Ponzi finance. Ponzi finance is feasible if and only if the net riskless rate is negative. ${ }^{10}$ This suggests that, after all, the riskless rate may be an important variable in assessing whether Ponzi finance is feasible or not. The last example shows that this guess would also be wrong.

\section{A fourth example: serially correlated returns in storage}

We consider the same storage economy, but now allow for serially correlated returns on storage. ${ }^{11}$ The reason for doing this will be clear later. More specifically, we assume that the rate of return on storage follows a geometric $A R(1)$ process:

$$
R_{t+1}=R_{t}^{\rho} \epsilon_{t+1}
$$

where $\rho \in(0,1)$ measures the persistence of macroeconomic shocks, and $\epsilon_{t+1} \epsilon$ $(\epsilon, \bar{\epsilon})$ is a positive i.i.d. random variable. It follows that there exists a long run, stable distribution of the storage rate with finite support on the interval $(\underline{R}, \bar{R})$, where $\underline{R}=\underline{\epsilon}^{1 /(1-\rho)}$ and $\bar{R}=\bar{\epsilon}^{1 /(1-\rho)}$.

From Zilcha's criterion, taking the logarithm and the unconditional expectation of both sides of (5.1), this economy is dynamically efficient if and only if

$$
\mathrm{E} \ln R_{t}=\frac{\mathrm{E} \ln \epsilon_{t}}{1-\rho} \geq 0
$$

9. Or, if we had used the preferences of section 2, if consumers are sufficiently risk averse.

10. This result is closely related to Koda's [1984] characterization in this model of the existence of monetary equilibria with constant money supply.

11. This example is a direct application of Gale [1990] 
Again, we assume this condition to be satisfied, and consider the following debt Ponzi game. At time 0 , the government issues some debt in the form of two-period bonds, titles to one unit of good two periods later. At time 1, the government buys back what are now one-period bonds, and pays with the proceeds of new issues of two-period bonds, and so on. To characterize the behavior of debt under this scheme, we must first determine the equilibrium prices of one- and two-period bonds.

The price at time $t$ of a two-period bond, issued at $t-1$ and maturing at $t+1$, is simply, from the first-order condition of the consumers, ${ }^{12}$

$$
\begin{aligned}
p_{1 t} & =\frac{\beta}{1-\beta} \mathrm{E}_{t}\left\{\frac{C_{1, t}}{C_{2, t+1}}\right\} \\
& =\mathrm{E}_{t} R_{t+1}^{-1} \\
& =R_{t}^{-\rho} \mathrm{E} \epsilon^{-1}
\end{aligned}
$$

Note-for later reference-that the price of a one-period bond is high when the current rate of storage is low-because a low return on storage today creates the expectation of a low future return. The price at time $t$ of a newly issued two-period bond is

$$
\begin{aligned}
p_{2 t} & =\left(\frac{\beta}{1-\beta}\right)^{2} \mathrm{E}_{t}\left\{\frac{C_{1, t}}{C_{2, t+1}} \frac{C_{1, t+1}}{C_{2, t+2}}\right\} \\
& =\mathrm{E}_{t}\left(R_{t+1} R_{t+2}\right)^{-1} \\
& =R_{t}^{-\rho(1+\rho)} \mathrm{E} \epsilon^{-1} \mathrm{E} \epsilon^{-(1+\rho)} .
\end{aligned}
$$

Now consider the dynamic behavior of debt (or-trivially-the ratio of debt to first period endowment, as the endowment, $W$, is constant). At time t, debt satisfies:

$$
p_{2 t} B_{t}=p_{1 t} B_{t-1}
$$

so that

$$
B_{t}=\frac{R_{t}^{\rho^{2}}}{\mathrm{E} \epsilon^{-(1+\rho)}} B_{t-1}
$$

12. The optimal consumption profile satisfes, with logarithmic preferences, $C_{1, t} / C_{2, t+1}=$ $[(1-\beta) / \beta] R_{t+1}^{-1}$. 
Can the government then use Ponzi finance? More specifically, is there a set of parameters such that i) the economy is dynamically efficient, ii) the one-period net riskless rate is always positive, (iii) debt decreases every period regardless of the realized state? As we now show, the answer is yes.

Since the rate of return on storage is bounded from above by $\bar{R}$, a sufficient condition for debt to decrease every period is, using (5.4),

$$
\frac{\bar{R}^{\rho^{2}}}{\mathrm{E} \epsilon^{-(1+\rho)}}<1 \text {. }
$$

The condition for dynamic efficiency is given in (5.2). And a sufficient condition for the one-period gross riskless rate $1 / p_{1 t}$ to be greater than 1 (and the net riskless rate to be positive) is, simply, ${ }^{13}$ using (5.3),

$$
\frac{R^{\rho}}{\mathrm{E} \epsilon^{-1}}>1 \text {. }
$$

A simple numerical example shows that inequalities (5.2), (5.7) and (5.8) can be satisfied simultaneously. Suppose that the $\epsilon$ 's follow a two-point distribution: $\epsilon_{t}=(\underline{\epsilon}, \bar{\epsilon})$ with probability $(.5, .5)$. Let $\rho=.75$. Then all three conditions are satisfied. ${ }^{14}$ Ponzi finance using non-contingent two-period bonds is feasible, although the economy is dynamically efficient and the one-period net riskless rate is negative in every state.

Two notes before we teturn to the question of why Ponzi games are feasible in the last two examples, not in the first two. If we had assumed that the $\epsilon$ 's had unbounded support or that the rate of return on storage were following a random walk $(\rho=1)$, we could never make sure that debt decreased from one date to the next whichever the realized state. For instance, with lognormal productivity shocks, the upper bound $\bar{R}$ would be infinite, and inequality (5.7) could not be satisfied. And if we had assumed that the shocks were i.i.d. $(\rho=0)$, the twoperiod Ponzi debt game strategy would be equivalent, by arbitrage, to the oneperiod scheme examined in the previous section, and would be feasible if and only if the one-period net riskless rate were negative. ${ }^{15}$

13. By arbitrage, the rates of return on one-period bonds, and on old two-period bonds one year to maturity must be equal.

14. One can check that $R=.81$, and $\bar{R}=1.39$. The left-hand side of inequality (5.2) equals .09; that of (5.7), which provides an upper-bound on the rate of growth on the Ponzi game, equals .92 ; and that of (5.8), which gives a lower bound on the gross riskless rate, equals 1.39.

15. This can be easily seen by inspection of (5.3) and (5.4). 


\section{Conclusion}

Why do results differ between the first two and the last two examples? Under uncertainty, overlapping generation models differ from Ramsey economies in two ways. The first is that people have finite economic horizons. The second is that markets are incomplete. In all four examples, the condition that dynamic efficiency holds rules out the capital overaccumulation which may arise from the first feature. The difference between the two sets of examples comes from the second feature. In the first two examples, incomplete markets do not matter, and thus the economy is Pareto optimal. In the last two, they do, and debt is Pareto improving. We consider these propositions in more detail.

In all four examples, the overlapping generation structure implies that the young cannot enter insurance contracts with the old so as to share risk in the first period of their life. But in the first two, the consumption of the young and the consumption of the old are perfectly correlated, suggesting that there is no room anyway for further risk sharing. Indeed, it is easy to show that the outcome in the first two examples is Pareto optimal. Following the previous literature, ${ }^{16}$ define a Pareto optimal allocation in this context as an allocation which maximizes some social welfare function, the sum of utilities of consumers for some set of weights. It is easy to check that the decentralized allocation in our first two examples maximizes the following social welfare function

$$
\mathrm{E}_{t}\left[\sum_{s=0}^{\infty}(1+\theta)^{-s}\left((1-\beta) \ln C_{1, t+s}+\beta \mathrm{E}_{t+s} \ln C_{2, t+s+1}\right)\right]
$$

where $\theta$ is defined as earlier and is therefore positive under dynamic efficiency. Thus, the economy is Pareto optimal, and there is no way to improve the welfare of current generations without hurting some future generation. Thus the government cannot play any Ponzi game, no matter what the average tiskless rate, or the expected value of the debt-to-GNP ratio.

This is not the case in the last two examples. As we saw in the third example, technological uncertainty falls only on the old at time $t$, while the consumption of the young remains constant. This suggests room for debt to provide such insurance, and this indeed the case. This has been emphasized by Gale [1990] who has shown that in the context of that example, the government can not only issue and rollover debt, but further issue new debt every period so as to maintain

16. See, for instance, Peled [1982], Aiyagari and Peled [1988], or Gottardi [1990]. 
a constant debt-to-endowment ratio. Not only is such a policy feasible but it is - Pareto improving, as long as the amount of debt does not lead to a positive riskless rate. This can be seen easily. Carrying a constant amount of debt at a negative riskless rate is equivalent to transfering a constant amount, $\tau$ from the young to the old. It is easy to check that the condition for such a transfer to increase expected utility is that the riskless rate be negative. ${ }^{17}$ Put another way, the reason why the government is able to play a Ponzi game is that bonds provide insurance and require a low rate of return. (This conclusion is similar to that in Bertocchi [1991], who focuses on the equivalent phenomenom of bubbles.) The role for non contingent debt to provide insurance may however be quite limited (or not present at all). This explains the role of the debt in the last example. When returns to storage are positively correlated, a low realization is associated with a lower equilibrium riskfree rate of return next period and thus a high price of one-period bonds. Thus, issuing two period bonds and buying them back as oneperiod bonds provides insurance to the old. The price they get for their bonds is high when the returns to storage are low. This suggests that there may be an optimal maturity for bonds, a line that has been explored by Gale. Indeed, this suggests the issuance of explicitly contingent bonds to provide the needed insurance. And under those conditions, the government may well be able to issue and rollover debt.

So we can return to our initial question. The average riskless rate may be a poor guide as to whether permanent rollover of debt is feasible. It may be negative while Ponzi games are infeasible, or positive while Ponzi games are feasible. The evolution of the expected debt-to-GNP ratio may be similarly misleading. Whether or not governments can rollover debt in dynamically efficient economies depends on whether the issuance of public debt can partially substitute missing markets. While the overlapping structure provides a rationale for why markets may be missing, there are many other, and perhaps more empirically relevant reasons, including asymmetric information, why markets may be missing and why public debt may be playing a useful role. ${ }^{18}$ In those cases also, the government may be able to play a Ponzi game.

17. The proof is immediate and holds for a general utility function. Expected utility when an intergenerational transfer of size $\tau$ takes place is $U=\mathrm{E} u[W-K(\tau)-\tau, \tilde{R} K(\tau)+\tau]$. Straightforward algebra shows that $d U / d \tau>0$ as long as $R^{f}<1$.

18. For instance, Woodford [1986], Scheinkman and Weiss [1986] and Kocherlakota [1990] provide examples of economies with infinitely-lived agents in an unbacked fiat currencyequivalent to a debt Ponzi game-may substitute for an exogenously closed market. 


\section{References}

Abel, A., Mankiw, N. G., Summers, L. H., and Zeckhauser, R. J., 1989, Assessing dynamic efficiency: theory and evidence, Review of Economic Studies, 56, 1-20.

Aiyagari, S. R. and Peled, D., 1988, Dominant root characterization of pareto optimality and the existence of monetary equilibria in stochastic overlapping generations models, mimeo, Federal Reserve Bank of Minneapolis.

Bertocchi, G., 1991, Bubbles and inefficiencies, Economics Letters, 35, 117-122.

Blanchard, O. J., 1990, Comments on Douglas Gale, The efficient design of public debt, in "Issues in debt management" (Dornbusch R. and M. Draghi, eds.), forthcoming.

Blanchard, O. J. and Fischer, S., 1989, Lectures on Macroeconomics, MIT Press.

Bohn, H., 1990, The sustainability of budget deficits in a stochastic economy, mimeo, The Wharton School, University of Pennsylvania.

Cass, D., 1972, On capital overaccumulation in the aggregative neoclassical model of economic growth: a complete characterization, Joumal of Economic Theory, 4, 200223.

Diamond, P., 1965, National debt in a neoclassical growth model, American Economic Review, 55, 1126-1150.

Gale, D., 1990, The efficient design of public debt, in "Issues in debt management" (Dornbusch R., and M. Draghi, eds.), forthcoming.

Galli, G. and Giavazzi, F., 1990, Debito publico, tassi d'interesse e disinflazione, mimeo, Banca d'Italia.

Gottardi, P., 1990, On stationary monetary equilibria in overlapping generations models with incomplete markets, Discussion paper 155.

Kocherlakota, N. R., 1990, Bubbles and constraints on debt accumulation, mimeo, University of lowa.

Koda, K., 1984, A note on the existence of monetary equilibria in overlapping generations models with storage, Joumal of Economic Theory, 34, 388-395.

Peled, D., 1982, Informational diversity over time and the optimality of monetary equilibria, Joumal of Economic Theory, 28, 255-274.

Scheinkman, J. and Weiss, L., 1986, Borrowing constraints and aggregate economic 
activity, Econometrica, 54(1), 23-46.

Selden, L., 1978, A new representation of preferences over 'certain $x$ uncertain' consumption pairs: The 'ordinal certainty equivalent' hypothesis, Econometrica, 46, 1045-1060.

Summers, L., 1984, Unpublished notes, mimeo, Harvard University.

Weil, P., 1987, Confidence and the real value of money in an overlapping generation economy, Quarterly Journal of Economics, CII(1), 1-22.

Weil, P., 1990, Non-expected utility in macroeconomics, Quarterly Joumal of Economics, CV(1), 29-42.

Woodford, M., 1986, Expectations, finance and aggregate instability, Oxford University Press, New York.

Zilcha, I., 1990, Characterizing efficiency in stochastic overlapping generations models, mimeo, The University of Tel-Aviv, August 1990. 